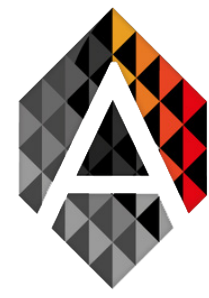

\title{
Impact of Sparse and Dense Deployment of Nodes Under Different Propagation Models in Manets
}

\author{
Altaf Hussain, Tariq Hussain*, Iqtidar Ali, Muhammad \\ Rafiq Khan
}

Department of Computer Science and IT, The University of Agriculture, Peshawar 25130, Pakistan altafkfm74@gmail.com, uom.tariq@gmail.com*, iqtidar@aup.edu.pk, muhdrafiq388@ gmail.com

$\begin{array}{ll}\text { KEYWORD } & \text { ABSTRACT } \\ \text { MANET; OLSR; } & \text { Mobile Ad-hoc Network (MANET) is the most emerging and fast-expanding } \\ \text { Propagation } & \text { technology in the last two decades. One of the major issues and challenging } \\ \text { Models; Sparse; } & \text { areas in MANET is the process of routing due to dynamic topologies and high } \\ \text { Dense } & \text { mobility of mobile nodes. The efficiency and accuracy of a protocol depend } \\ & \text { on many parameters in these networks. In addition to other parameters node } \\ & \text { velocity and propagation models are among them. Calculating signal strength } \\ \text { at the receiver is the responsibility of a propagation model while the mobility of } & \text { nodes is responsible for the topology of the network. A huge amount of loss in } \\ \text { performance is occurred due to the variation of signal strength at the receiver } \\ \text { and obstacles between transmissions. In this paper, it has been analyzed to } \\ \text { check the impact of different propagation models on the performance of } \\ \text { Optimized Link State Routing (OLSR) in Sparse and Dense scenarios in } \\ \text { MANET. The simulation has been carried out in NS-2 by using performance } \\ \text { metrics as average packet drop average latency and average Throughput. The } \\ \text { results predicted that propagation models and mobility have a strong impact on } \\ \text { the performance of OLSR in considered scenarios. }\end{array}$

\section{Introduction}

Mobile Ad-hoc Networks is known as a wireless ad hoc network (WANET). The nodes of MANETs can easily move from one place to another that's why this is called mobile nodes network (Amjad

Altaf Hussain, Tariq Hussain, Iqtidar Ali and Muhammad Rafiq Khan Impact of Sparse and Dense Deployment of Nodes Under Different Propagation Models in Manets
ADCAIJ: Advances in Distributed Computing and Artificial Intelligence Journal Regular Issue, Vol. 9 N. 1 (2020), 61-84 eISSN: 2255-2863 - https://adcaij.usal.es Ediciones Universidad de Salamanca - CC BY-NC-ND 
et al., 2015). The nodes are mobile in general that involve no external entity i.e. no infrastructure for the arrangement of nodes. Each node in this network operates as a host and router. That usually has a routable networking environment on top of a Link Layer ad hoc network. MANET consist of self-healing network, self-forming, peer-to-peer. MANETs in 2000-2015 typically communicate at radio frequencies rang was $30 \mathrm{MHz}$ to $5 \mathrm{GHz}$ (Alnumay, Ghosh, \& Chatterjee, 2019; Draves, Padhye, \& Zill, 2004).

Wireless networks are performed a significant character in the field of wireless communication (Jacquet et al., 2001). The wireless network is used for armed communication at the battlefield, Emergency operation and manufacturing uses such as rescue and crowd control. The change between wired and wireless networks is the communication way. The physical medium required under wired networks. Although wireless networks don't exist as a physical medium. Wireless networks developed very standardly in diverse uses in the subsequent issues such as easy installation, dependability, and bandwidth, cost, reliability, security, total necessary energy and efficiency of the network. All networks are having static infrastructures. The most common fixed centralized entity-based networks are cellular networks, Wi-Fi, Wi-MAX, cordless telephone, RADAR and satellite communication, etc (Alnumay et al., 2019; Chattopadhyay \& Agarwal, 2018; Khandakar, 2012). Upcoming variation in the hardware components (generation) wireless ad-hoc networks are performing an outstanding character in the rapid placement of autonomous movable user, effective and dynamic communication for emergency operation of tragedy relief efforts, martial network. Ad-hoc networks have no such combine topologies that pave a huge area of interest. These topologies can evolve randomly and dynamically. Some fixed and static routing schemes that are usually utilized for internet wireless network. These cannot be utilized to ad-hoc networks directly due to some specific and general considerations that are not in every case to every dynamically evolving network and that may also be not factual for movable users. MANETs have no base station and use multi-hop communication with each other. As MANETs does not depends on any physical links, at any position of time and of any category of requirement. MANETs can be set up and used, because common network requires pre-planning but MANETs does not(Chattopadhyay \& Agarwal, 2018) (DE, 2003) Another huge attribute of MANETs is the capability of changing the size of network as per requirement i.e. number of nodes can be attached and any number of nodes can be disconnected. All the nodes are related in functionality and can act either as a node or a router resulting in an asymmetric environment (Dhoutaut, Régis, \& Spies, 2006). Any communication is level to natural disasters and can destroy it. So, to keep the resources on infrastructure, MANETs can be used in those areas which are extremely level to natural disasters leading to a huge amount of success in cost-saving (Katagiri, Onose, Sato, Inage, \& Fujii, 2019). Nodes of the MANETS can travel from one location to another with a different rush. The set of connection topology can be different randomly. In MANET node can route packets regardless of this active location. Nodes are fit to create any statement possible even after shifting their location (Clausen \& Jacquet, 2003). To manage the network is spread between all the nodes of the network and there is not any middle node that is dependable for all communication. Each node is similarly accountable for creating the declaration possible. Nodes themselves can decide their own (Rahul, Bansal, \& Kapoor, 2019). In most of the cases, the nodes in the MANET are small computing devices such as laptops, mobiles, etc. These devices are having low CPU capabilities, low power and small memory (Sood, Baroudi, Zhang, Liebeherr, \& Sarris, 2018). Due to MANET's technology, it doesn't require any infrastructure and maybe recognized simply in any environmental area. Thus, these networks are very helpful in the battlefield of military combat to build the communication probable among the armed forces, (Head Quarters) HQs and military automobiles. MANETs are considered necessary by some commercial organizations to design and develop

Altaf Hussain, Tariq Hussain, Iqtidar Ali and Muhammad Rafiq Khan Impact of Sparse and Dense Deployment of Nodes Under Different Propagation Models in Manets
ADCAIJ: Advances in Distributed Computing and Artificial Intelligence Journal Regular Issue, Vol. 9 N. 1 (2020), 61-84 eISSN: 2255-2863 - https://adcaij.usal.es Ediciones Universidad de Salamanca - CC BY-NC-ND 
the cooperative and collaborative computing. MANETs can compose the connection among devices by some occasion of the period. Thus, these networks are valuable to create the communication probable near by i.e. in a meeting or laboratory (Bhoyroo \& Bassoo, 2016). A private region network needs tiny collection and incomplete digit of stations attached. Bluetooth equipment can be helpful in the creation link among devices then arrangements to follow the schemes of MANETs(Gruber, Knauf, \& Li, 2004; Pal, Dutta, Chakrabarti, Singh, \& Sadhu, 2019).

Ad-hoc networks have no such combine topologies that pave a huge area of interest. These topologies can evolve dynamically and randomly. Some fixed and static routing schemes that are usually utilized for internet wireless network. These cannot be utilized to ad-hoc networks directly due to some specific and general considerations that are not in every case to every dynamically evolving network and that may also be not factual for movable users (Draves et al., 2004; Malik, Verma, \& Pal, 2012). Wireless networks developed very standardly in diverse uses in the subsequent issues such as easy installation, dependability, and bandwidth, cost, reliability, total necessary energy, security and efficiency of the networks. All networks are having static infrastructures. The most common fixed centralized entity-based networks are cellular networks, Wi-Fi, Wi-MAX, cordless telephone, RADAR and satellite communication, etc. (Khandakar, 2012). The Near-term digital radio performed trials of networks including over 70 nodes in the late 1990s and was later fielded in the United States Army (Draves et al., 2004; Prakash, Gupta, \& Kumar, 2017). MANET is broadly three types are IMANET, VANETs, and FANETs. These are shown in the Figure and explained accordingly in the given subsections that shows the overall types of MANET or WANET (Wireless Ad-hoc Network) (Corson, 1999) A variety of algorithms and routing schemes were suggested and their efficiency in the aspect of many network surroundings and transfer the condition were studied and compared (Nabou, Laanaoui, \& Ouzzif, 2018; Xiang \& Yang, 2018).

\subsection{Routing Protocols in MANETs}

MANET routing schemes are mostly separated into five classes these are Reactive, Proactive, Hybrid, Hierarchal and Position-based routing. MANETs face numerous challenges; due to node mobility, resource constraints, unreliable links, wireless radio medium, lack of infrastructure, absence of centralized entity and design of conventional routing protocols. Therefore, for designing MANET some issues should be considered consideration first (Mishra, Dash, Hota, \& Panda, 2017; Patil, 2016). The commercial achievement of cellular communication has controlled a powerful consideration among wireless engineers in thoughtful and forecasting radio propagation features in many urban and suburban regions and even without buildings. Henceforth, it is very important to have the ability of causal best possible node location, gaining proper rates of data and approximating their area of paving (coverage), without leading a series of propagation amounts that are costly and consuming time. Therefore, it is essential to improve the successful model of propagation for providing the stricture guidelines for many systems. In Mobile Ad-Hoc networks, routing, rate variation, topology manage and interference managing perform a remarkable part for communication. Research on planning a link metric that signifies time unreliable wireless connect excellence for wireless mesh routing has been dynamic (DE, 2003). While, the struggle to improve and design the effectiveness of the used routing algorithm has a little impact (Draves et al., 2004). MANETs can be simply generating to make communication probable in event of saving actions in case of a tragedy like fire, flood or quake in which other traditional infrastructure networks become dense. In Mobile Ad-Hoc networks, routing, rate variation, topology manage and interference managing perform a remarkable part for communication. Research

Altaf Hussain, Tariq Hussain, Iqtidar Ali and Muhammad Rafiq Khan Impact of Sparse and Dense Deployment of Nodes Under Different Propagation Models in Manets
ADCAIJ: Advances in Distributed Computing and Artificial Intelligence Journal Regular Issue, Vol. 9 N. 1 (2020), 61-84 eISSN: 2255-2863 - https://adcaij.usal.es Ediciones Universidad de Salamanca - CC BY-NC-ND 
on planning a link metric that signifies time unreliable wireless connect excellence for wireless mesh routing has been dynamic. While, the struggle to improve and design the effectiveness of the used routing algorithm has a little impact (Zhihua \& Bing, 2019).

\subsection{Propagation Models}

The model of propagation of the non-fading justifies for the detail that a radio signal must pave an increasing region by the time of the distance that is increasing to the sender. Instances are two-ray ground and free-space models of propagation. While on the other side, the propagation model of the fading calculates the power of the signal that is dependable on the actions of the node of frames of small-time. An amount of the statistical paradigm is utilized to describe fading in the settings of wireless and the major frequently utilized dissemination for large scale fading is shadowing. In this work of research, the three models of propagation have been utilized are Two ray ground, Shadowing propagation and Free space propagation(Sarkar, Ji, Kim, Medouri, \& Salazar-Palma, 2003; Sood et al., 2018).

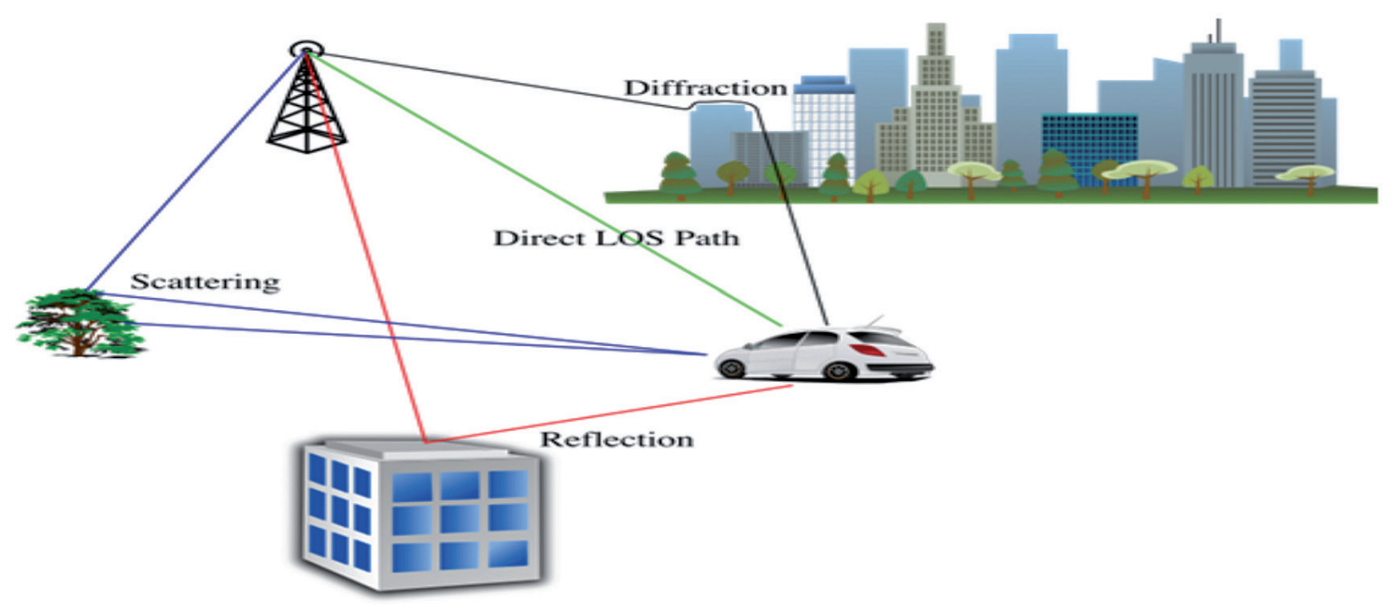

Figure 1: Scenario of Direct LoS, Reflection, Diffraction and Scattering (Eltahir, 2007)

\subsubsection{Shadowing Propagation Model}

This model of propagation utilizes the mathematical parameters for examining and analyzing the obtained energy assuming the power to have a chance up and down. It is the outcome that the obtained power of the signal altered because of the items obstructing the path of the propagation between the destinations (receiver) i.e. because of the effects of the fading. These variations are fortified power of local mean which is: the short-term average for excluding and eliminate the variations because of the multi-path fading. This type of version has two parts, the first part the mean gets authority at the distance $\mathrm{d}$ that is a path-loss $(\mathrm{dB})$ model utilizing a near-in distance which acts and stated by $\operatorname{Pr}(\mathrm{d})$ and $\operatorname{Pr}(\mathrm{do})$ correspondingly, while the second part of the model reflects and range of the gained power at fairly distance(Sarkar et al., 2003). Mathematically,

$$
\left.\frac{P_{r}(d)}{P_{r}\left(d_{o}\right)}\right|_{d B}=-10 \beta \log \left(\frac{d}{d o}\right)
$$

Altaf Hussain, Tariq Hussain, Iqtidar Ali and Muhammad Rafiq Khan Impact of Sparse and Dense Deployment of Nodes Under Different Propagation Models in Manets
ADCAIJ: Advances in Distributed Computing and Artificial Intelligence Journal Regular Issue, Vol. 9 N. 1 (2020), 61-84 eISSN: 2255-2863 - https://adcaij.usal.es Ediciones Universidad de Salamanca - CC BY-NC-ND 
Where $\beta$ is the path failure example that is mathematically determined by field size.

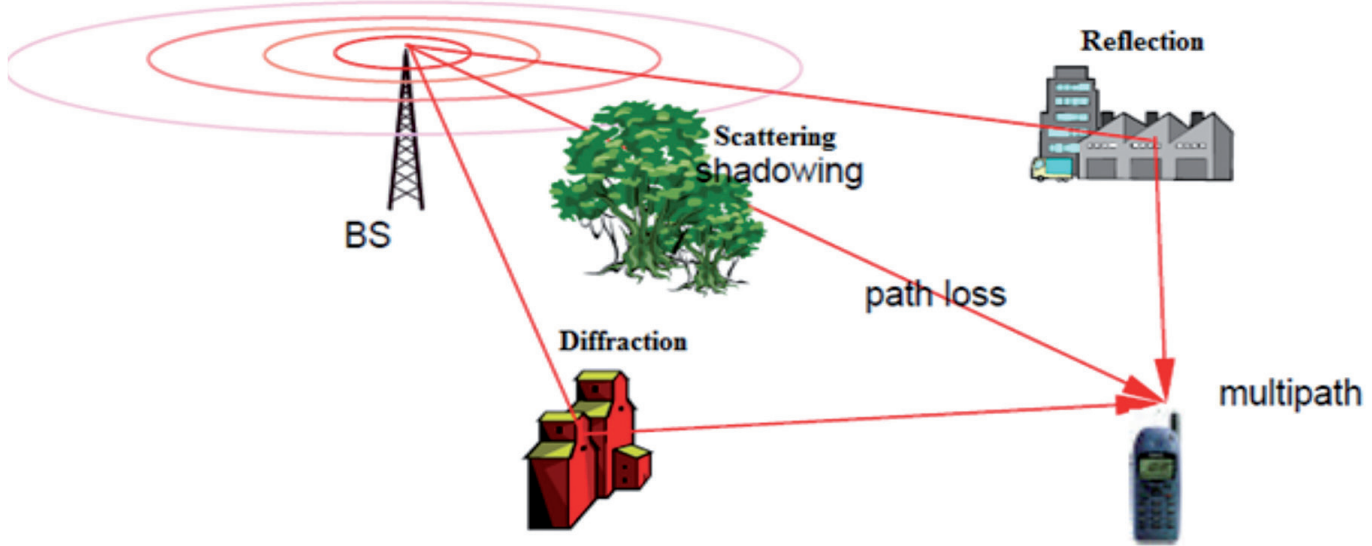

Figure 2: Scenario of Travel of signal in Propagation Models (Khan et al., 2017)

\subsubsection{Two Ray ground Propagation Model}

A single line-of-sight (LOS) path between two movable nodes is rarely the simple mean of broadcasting. Thus, the model of propagation of two-ray ground assumes equally the shortest path a reflection of the ground path which provides more correct calculation at an extended range (distance) than the model of free space (Sarkar et al., 2003). The acknowledged authority at distance (d) is projected by:

$$
P_{r}(d)=\frac{P_{t} G_{t} G_{r} h_{t}^{2} h_{r}^{2}}{d^{4} L}
$$

Where Pt is the power of the transmitted signal, $G_{t}$ and $G_{r}$ are the gains of the antenna transmit and receive, $h_{t}$ and $h_{r}$ are heights of received and transmitted antenna respectively and $L$ is the arrangement failure.

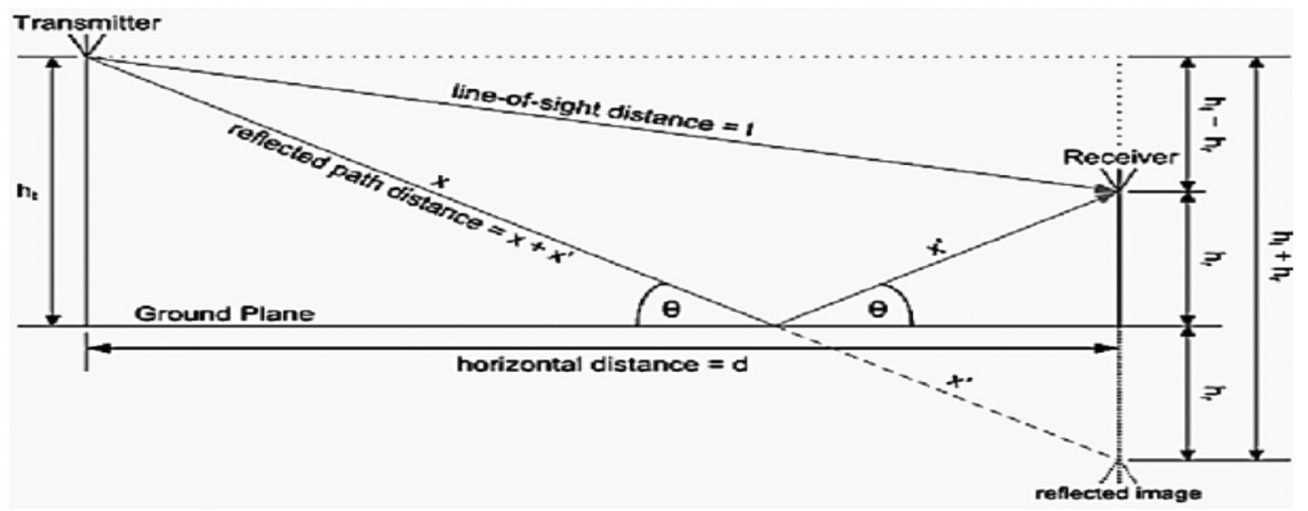

Figure 3: Scenario of Two Ray Ground Propagation Model (Eltahir et al., 2007)

Altaf Hussain, Tariq Hussain, Iqtidar Ali and Muhammad Rafiq Khan Impact of Sparse and Dense Deployment of Nodes Under Different Propagation Models in Manets
ADCAIJ: Advances in Distributed Computing and Artificial Intelligence Journal Regular Issue, Vol. 9 N. 1 (2020), 61-84 eISSN: 2255-2863 - https://adcaij.usal.es Ediciones Universidad de Salamanca - CC BY-NC-ND 


\subsubsection{Free Space Model}

This is a model of a huge level. The gained power is just reliant on the power of the transmitter, the antenna's gains and the distance between the destination and the source. It takes into consideration the majority for the detail that the signal of radio waves transfers away from the sender that has to confront the best region. Consequently, the power of the received signal minimizes the distance of the square level. The model of propagation of free space undertakes the best propagation form that there is only one perfect LOS path between the receiver and the transmitter. H.T Friis suggested equation 3 for the calculation of the gained power of the signal in the model of Fee Space at the distance (d) from the transmitter (Schmitz \& Wenig, 2006). This level can be calculated by using equation 3.

$$
P_{r}(d)=\frac{P_{t} G_{t} G_{r} \lambda^{2}}{(4 \pi)^{2} d^{2} L}
$$

Where $P_{t}$ is the power of the transmitted signal. $G_{t}$ and $G_{r}$ are the gains of the antenna of the receiver and the transmitter separately, where $\lambda$ is the wavelength and $\mathrm{L}(\mathrm{L} \geq 1)$ is the system loss. It is usual to choose $\mathrm{G}_{\mathrm{t}}=\mathrm{G}_{\mathrm{r}}=1$ and $\mathrm{L}=1$ in the simulations of NS-2.

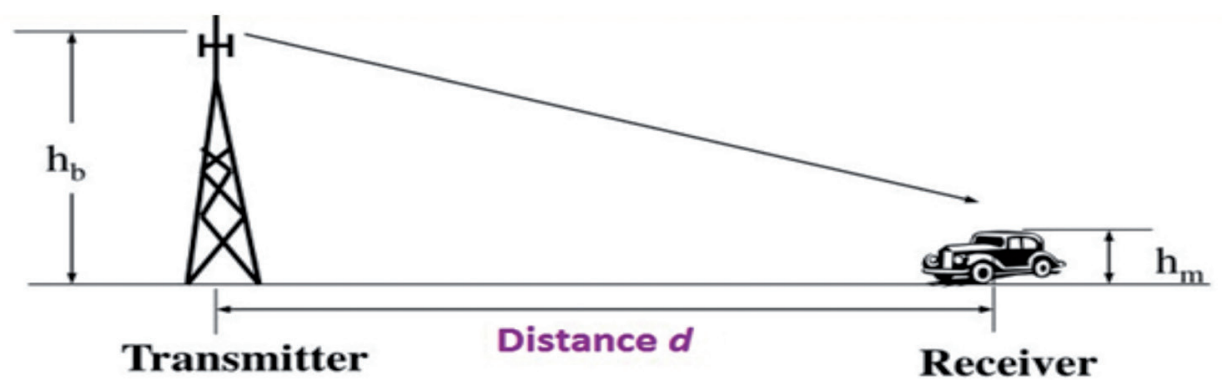

Figure 4: Scenario of Free-Space Propagation Model (Khan et al., 2017)

\subsection{Our contribution}

In recent decades several members of the research community have analyzed and evaluated the performance of routing protocols under unique circumstances to check the efficiency and stability of routing by varying several simulation parameters. The role of the propagation model is of much importance as they keep the nodes connected. A huge amount of loss occurred due to the variation of signal strength at the receiver and obstacles between transmissions. So, it is of great importance to observe how the performance of routing is affected by different propagation models. Secondly, to investigate the impact of propagation models in sparse and dense topologies. The focus of this work will be to evaluate the performance using different models of propagation i.e. Two Ray ground, shadowing and free space model using Optimized Link State Routing (OLSR) scheme in urban sparse and dense topologies.

- To investigate the performance of Shadowing, Two Ray and Free Space radio models of propagation for sparse and dense environments.

- To analyze and report the results in terms of performance evaluation parameters i.e. Average Throughput, average latency and Average packet drop during the simulation for each scenario.

Altaf Hussain, Tariq Hussain, Iqtidar Ali and Muhammad Rafiq Khan Impact of Sparse and Dense Deployment of Nodes Under Different Propagation Models in Manets
ADCAIJ: Advances in Distributed Computing and Artificial Intelligence Journal Regular Issue, Vol. 9 N. 1 (2020), 61-84 eISSN: 2255-2863 - https://adcaij.usal.es Ediciones Universidad de Salamanca - CC BY-NC-ND 


\section{Related Literature}

According to researchers (Jubair, Khaleefah, Mostafa, \& Mustapha, 2018) suggested that the efficiency of some well-known ad-hoc schemes under diverse propagation models in MANETs. Under the different mobility models, the concerned study was conducted, these models were free space model, shadowing and two ray ground. Impact of these models on the existing routing schemes DSDV, AODV and DSR routing scheme. A successful mobility model requires that it shows the moving performance of every mobile node. The experimental analysis of the simulation had shown the open choice of the existing propagation model that acts and has a specific major role in the selection of the routing schemes, since it may cause the effect harmfully on the performance of the concurrent scenario. They have taken different protocols for the sake of propagation models both proactive and reactive protocols for the concerned scenario the main difference is that we have taken only OLSR protocol that belongs to the proactive category with the help of FTP and TCP agents.

The authors in (Venkataramana, Rao, \& Setty, 2015) focused on Ricean, Rayleigh, Shadowing and Nakagami models by noticing the development of the routing layer presentations based on the features of the physical layer. For this reason, the author's matched the efficiency and performance of some routing schemes (DSDV, AODV, and DSR) for every propagation model as mentioned and then showed the simulation outcomes of the effect of diverse radio propagation model on the efficiency of the ad-hoc network. Rendering to the simulation results, it may be confirmed that the selection of the propagation model had a huge effect on the routing scheme actions and efficiency. The presentation reduces quickly when the disappearing model, mainly Ricean, Rayleigh, Shadowing, and Nakagami are considered. According to the results of the routing protocols' performance, the author's established out that there exists no better scheme between the others all situations and the measuring principles. Similarly, no subject how numerous links there are, it was noticed that AODV and DSDV have an improve delay in terms of DSR. They have focused on improving the performance of routing protocols like DSDV, AODV, and DSR for propagation models. They have been taken the Ricean, Rayleigh, Shadowing and Nakagami models. Our research work is different from the above because we have taken the OLSR protocol and different models.

The research in (Patil, 2016) presented the efficiency of the different routing schemes like DSR, DSDV, AOMDV and AODV schemes from the perspective of three types of different models of mobility based on models of propagations that were shadowing, Nakatomi and two ray ground. The experimental results of the simulation indicated that schemes have preserved their essential features through diverse settings but with significant modification and changes when the energy of diverse models of propagation encountered. Considering unstable mobility scenario 1, AODV scheme in the mobility model Nakagami is talented based on throughput and PDR, though DSDV in mobility model Nakagami effectively performed other schemes based on power and delay parameters. Considering, unstable travel load setting DSR scheme in mobility model Nakagami is the most effective based on the consumption of energy and PDR. Generally, it can be done that schemes have preserved their inhabitant and characteristic features throughout divergent settings, but the key changes and modifications based on the impact of diverse environments of propagation.

According to researchers in (L. U. Khan, Khan, Khan, Khan, \& Pirzada, 2013) proposed that the radio propagations model that includes shadowing model, free space model, and two ray ground model

Altaf Hussain, Tariq Hussain, Iqtidar Ali and Muhammad Rafiq Khan Impact of Sparse and Dense Deployment of Nodes Under Different Propagation Models in Manets
ADCAIJ: Advances in Distributed Computing and Artificial Intelligence Journal Regular Issue, Vol. 9 N. 1 (2020), 61-84 eISSN: 2255-2863 - https://adcaij.usal.es Ediciones Universidad de Salamanca - CC BY-NC-ND 
are evaluated and analyzed as a core contribution. These models are implemented in MANETs environments in the light of changing traffic and mobility parameters. The effects of the different radio propagation models are analyzed over the destination-sequenced distance-vector (DSDV) routing protocols. In DSDV, the sequence numbers are used to maintain routes and new routes overcome the old routes when sequence numbers of the old routes become obsolete. To better understand the behavior of radio propagation models, simulations are conducted using Network Simulator-2. The metrics used in simulations include the ratio of packet delivery, average delay, throughput, and packet drop ratio concerning the mobility and pause time parameters. The obtained results indicate that the two-ray ground model is more suited for the DSDV protocol than the random waypoint model in terms of packet success ratio, data packets sent throughput and average network delay. Further, the model has a lower value for packets dropped than the Free Space and Shadowing models at higher pause times. They have been proposed the propagation models for changing the traffic light used the DSDV protocol. They have been checked which model gives the best and accurate performance. Our research scenario is different from these works because we have been taken OLSR protocol and have been different parameters.

According to researchers in (Shutimarrungson \& Wuttidittachotti, 2019) investigated the result of two non-fading models of propagation named free space and two ray ground model, by the key features and outcomes of the ad-hoc routing schemes like DSR, AODV and Location-Aware Routing scheme in terms of average throughput, delay, and routing overhead. The authors observed that the act and efficiency of the LAR1 routing protocol is top, and the performance of DSR protocol is worst as radio verity increase. In a comparison of two ray ground and free space models, two ray ground models are best in the case of AODV and DSR, but in the case of LAR1 free space, the model gives the best effect. Further, this study would be extended to investigate the performance of LAR1 routing protocols in the fading propagation model.

The author in (M. Khan, Majeed, \& Muhammad, 2017) proposed that three radio propagation models that include the shadowing model, free space model, and two ray ground model are evaluated and analyzed as a core contribution. These models are implemented in MANETs environments in the light of changing traffic and mobility parameters. The effects of the different radio propagation models are analyzed over the (DSDV) routing protocols. In DSDV, the sequence numbers are used to maintain routes and new routes overcome the old routes when sequence numbers of the old routes become obsolete. To better understand the behavior of radio propagation models, simulations are conducted using Network Simulator-2. The metrics used in simulations include the ratio of packet delivery, throughput, average delay, and packet drop ratio concerning the pause time and mobility parameters. The obtained results indicate that the two-ray ground model is more suited for the DSDV protocol than the random waypoint model in terms of packet success ratio, data packet sent, and average network delay, throughput. Further, the model has a lower value for packets dropped than the Free Space and Shadowing models at higher pause times.

The author in (Poonia, 2017) examined the study of Two Ray Ground and Nakagami radio propagation models for vehicular ad hoc networks in Indian Scenarios as well as to find the best efficient model, which is more suitable in various scenarios. The output of this research will be beneficial for applying efficient models on the realistic highway scenario, especially traffic caused by the four-wheelers. This model will also be fruitful for avoiding heavy road congestion and highway road accidents

Altaf Hussain, Tariq Hussain, Iqtidar Ali and Muhammad Rafiq Khan Impact of Sparse and Dense Deployment of Nodes Under Different Propagation Models in Manets
ADCAIJ: Advances in Distributed Computing and Artificial Intelligence Journal Regular Issue, Vol. 9 N. 1 (2020), 61-84 eISSN: 2255-2863 - https://adcaij.usal.es Ediciones Universidad de Salamanca - CC BY-NC-ND 
caused by a high and unbalanced speed of traffic as well as the various road conditions, like path holes and road barriers, etc.

The research conducted in (Sood et al., 2018) used ray-tracing and parabolic equation models of 2.4 GHz propagation along the tunnel and open-air sections of London Underground to evaluate the performance of a communications-based train control (CBTC) system. For comparison, they considered existing path loss models for tunnel environments and investigate whether they can provide enough accuracy to be used for network protocol design. They have shown that physics-based models lead to reliable predictions at the network level, similar infidelity to using measured data and unlike using simplified channel models of the path loss exponent type.

The research conducted in (Zhihua \& Bing, 2019) presented invention relates to a method for predicting indoor three-dimensional space signal field strength by an outdoor to indoor propagation model, which comprises the steps of establishing a three - dimensional space scene model from a transmitting base station to a target building: predicting space field strength of an outer envelope of the target building according to an extended COST-231-Walfisch-Ikegami propagation model; generating, on the outer envelope of the target building, a series of outdoor to indoor virtual rays by a certain resolution; simulating a propagation procedure of the virtual rays using a ray-tracing propagation model algorithm, to predict three-dimensional space signal field strength in the target building. In the present invention, an extended COST231-Walfisch Ikegami propagation model is adopted for the transmitting base station and the outdoor region of the target building, while a ray-tracing propagation model algorithm is adopted for the indoor region of the target building, which effectively combines an outdoor empirical propagation model and an indoor deterministic propagation model so that a good equilibrium is achieved between calculation efficiency and calculation accuracy and the algorithm has strong engineering applicability.

Table 1: Comparison of literature survey with the proposed work.

\begin{tabular}{|l|l|l|l|}
\hline $\begin{array}{c}\text { Authors } \\
\text { and Year }\end{array}$ & \multicolumn{1}{|c|}{$\begin{array}{c}\text { Methodology, Tools } \\
\text { and Techniques }\end{array}$} & \multicolumn{1}{c|}{ Advantages } & \multicolumn{1}{c|}{ Limitations } \\
\hline $\begin{array}{l}\text { Jubair } e t \\
\text { al., } 2018\end{array}$ & $\begin{array}{l}\text { They had taken OLSR with FTP and } \\
\text { TCP as an agents for analysis of DSDV, } \\
\text { AODV and DSR both reactive and } \\
\text { proactive protocols. They have taken } \\
\text { propagation models but along with that } \\
\text { mobility models have also been taken } \\
\text { into account. Their work have similarity } \\
\text { with the proposed work but the only dif- } \\
\text { ference is that they have tested mobility } \\
\text { models not propagation models. The } \\
\text { propagation models have only taken for } \\
\text { signal propagation for a protocol to per- } \\
\text { form its duty based on it. }\end{array}$ & $\begin{array}{l}\text { But sill it has lim- } \\
\text { possess tremendous } \\
\text { advantage }\end{array}$ & $\begin{array}{l}\text { itations because } \\
\text { by using so many } \\
\text { protocols can lead } \\
\text { to network traffic } \\
\text { and overhead prob- } \\
\text { lem. It also uses } \\
\text { the flooding mecha- } \\
\text { nism which creates } \\
\text { overhead, delay and } \\
\text { packet loss. }\end{array}$ \\
\hline
\end{tabular}

Altaf Hussain, Tariq Hussain, Iqtidar Ali and Muhammad Rafiq Khan Impact of Sparse and Dense Deployment of Nodes Under Different Propagation Models in Manets
ADCAIJ: Advances in Distributed Computing and Artificial Intelligence Journal Regular Issue, Vol. 9 N. 1 (2020), 61-84 elSSN: 2255-2863 - https://adcaij.usal.es Ediciones Universidad de Salamanca - CC BY-NC-ND 


\begin{tabular}{|c|c|c|c|}
\hline $\begin{array}{l}\text { Authors } \\
\text { and Year }\end{array}$ & $\begin{array}{l}\text { Methodology, Tools } \\
\text { and Techniques }\end{array}$ & Advantages & Limitations \\
\hline $\begin{array}{l}\text { Venkatara- } \\
\text { mana } \text { et al., } \\
2015\end{array}$ & $\begin{array}{l}\text { They have used Ricean, Rayleigh, Shad- } \\
\text { owing and Nakagami models with the } \\
\text { help of DSDV, AODV, and DSR routing } \\
\text { protocols. These protocols were tested } \\
\text { under these propagation models and yet } \\
\text { they have concluded that OLSR gives } \\
\text { better results because at the end they } \\
\text { have also used OLSR for evaluation }\end{array}$ & $\begin{array}{l}\text { The main advantage } \\
\text { is that this work } \\
\text { shows similarity to } \\
\text { the proposed work } \\
\text { i.e., it indicates that } \\
\text { OLSR is better than } \\
\text { DSDV,AODV and } \\
\text { DSR }\end{array}$ & $\begin{array}{l}\text { These models } \\
\text { are outdated like } \\
\text { Rayleigh, Nakagami } \\
\text { which are not accu- } \\
\text { rate as compared to } \\
\text { the proposed work } \\
\text { models }\end{array}$ \\
\hline $\begin{array}{l}\text { Naseerud- } \\
\text { din et al., } \\
2016\end{array}$ & $\begin{array}{l}\text { They have used DSR, DSDV, AOMDV } \\
\text { and AODV with the help of Nakagami } \\
\text { propagation model. }\end{array}$ & $\begin{array}{l}\text { The model shows } \\
\text { better results in PDR }\end{array}$ & $\begin{array}{l}\text { Due to outdated } \\
\text { model this work } \\
\text { lack the efficiency } \\
\text { and shows limited } \\
\text { performance }\end{array}$ \\
\hline $\begin{array}{l}\text { Khan et al., } \\
2013\end{array}$ & $\begin{array}{l}\text { They have used DSDV protocol for } \\
\text { evaluation of two ray ground, free space } \\
\text { and shadowing propagation models }\end{array}$ & $\begin{array}{l}\text { Their work is effi- } \\
\text { cient and matches } \\
\text { about } 90 \% \text { with the } \\
\text { proposed work }\end{array}$ & $\begin{array}{l}\text { The main limitation } \\
\text { is that they have } \\
\text { used DSDV which } \\
\text { gives poor perfor- } \\
\text { mance in contrast } \\
\text { with OLSR }\end{array}$ \\
\hline $\begin{array}{l}\text { Shutimar- } \\
\text { rungson } \\
\text { \& Wuttid- } \\
\text { ittachotti, } \\
2019\end{array}$ & $\begin{array}{l}\text { They have used AODV and DSR with } \\
\text { the help of LAR location aware rout- } \\
\text { ing. In their work they have focused on } \\
\text { finding the location of the target area or } \\
\text { node }\end{array}$ & $\begin{array}{l}\text { LAR.1 gives best } \\
\text { results in finding } \\
\text { the location and be } \\
\text { aware of the current } \\
\text { state of the node in } \\
\text { the network }\end{array}$ & $\begin{array}{l}\text { Their work lacks be- } \\
\text { cause they have fo- } \\
\text { cused on finding the } \\
\text { location like GPS } \\
\text { but the proposed } \\
\text { work differs from it }\end{array}$ \\
\hline $\begin{array}{l}\text { Khan et al., } \\
2017\end{array}$ & $\begin{array}{l}\text { They have used DSDV with the help of } \\
\text { NS-2 simulator }\end{array}$ & $\begin{array}{l}\text { DSDV protocol } \\
\text { gives best results } \\
\text { when the nodes are } \\
\text { nearby with each } \\
\text { other }\end{array}$ & $\begin{array}{l}\text { As already discussed } \\
\text { that DSDV gives } \\
\text { poor performance } \\
\text { in contrast with the } \\
\text { OLSR which is used } \\
\text { in proposed work }\end{array}$ \\
\hline $\begin{array}{l}\text { Poonia et } \\
\text { al., } 2017\end{array}$ & $\begin{array}{l}\text { They have examined Two Ray Ground } \\
\text { and Nakagami radio propagation for re- } \\
\text { alistic scenario of traffic in India }\end{array}$ & $\begin{array}{l}\text { It is the best idea by } \\
\text { using the models in } \\
\text { real world scenario }\end{array}$ & $\begin{array}{l}\text { The only lack it that } \\
\text { the proposed work } \\
\text { should be based on } \\
\text { simulated scenario } \\
\text { after the successful } \\
\text { implementation it } \\
\text { can be brought to } \\
\text { real world scenario }\end{array}$ \\
\hline
\end{tabular}

Altaf Hussain, Tariq Hussain, Iqtidar Ali and Muhammad Rafiq Khan Impact of Sparse and Dense Deployment of Nodes Under Different Propagation Models in Manets
ADCAIJ: Advances in Distributed Computing and Artificial Intelligence Journal Regular Issue, Vol. 9 N. 1 (2020), 61-84 eISSN: 2255-2863 - https://adcaij.usal.es Ediciones Universidad de Salamanca - CC BY-NC-ND 


\begin{tabular}{|c|c|c|c|}
\hline $\begin{array}{l}\text { Authors } \\
\text { and Year }\end{array}$ & $\begin{array}{l}\text { Methodology, Tools } \\
\text { and Techniques }\end{array}$ & Advantages & Limitations \\
\hline $\begin{array}{l}\text { Sood et al., } \\
2018\end{array}$ & $\begin{array}{l}\text { They have used the equation models } \\
\text { that computes the numerical values of } \\
\text { the signal. communications-based train } \\
\text { control (CBTC) system have been used } \\
\text { on } 2.4 \mathrm{GHz} \text { range of frequency }\end{array}$ & $\begin{array}{l}\text { Their work has giv- } \\
\text { en tremendous re- } \\
\text { sults by using CBTC } \\
\text { scheme }\end{array}$ & $\begin{array}{l}\text { The only limitation } \\
\text { is that they have } \\
\text { used only single } \\
\text { scheme for comput- } \\
\text { ing and calculation } \\
\text { of the signal strength }\end{array}$ \\
\hline $\begin{array}{l}\text { Zhihua et } \\
\text { al., } 2019\end{array}$ & $\begin{array}{l}\text { They have used COST-231-Wal- } \\
\text { fisch-Ikegami propagation model which } \\
\text { work for indoor scenario in. By using } \\
\text { the indoor 3D space for indoor to out- } \\
\text { door propagation }\end{array}$ & $\begin{array}{l}\text { The model has best } \\
\text { features it use high } \\
\text { range of frequency } \\
\text { for indoor and out- } \\
\text { door scenarios }\end{array}$ & $\begin{array}{l}\text { Their scenarios, } \\
\text { methods and tools } \\
\text { used are efficient } \\
\text { but limited because } \\
\text { COST-231 only } \\
\text { works when the both } \\
\text { transmitter and re- } \\
\text { ceive antennas have } \\
\text { the same size }\end{array}$ \\
\hline \multicolumn{4}{|c|}{ The Proposed Work } \\
\hline $\begin{array}{l}\text { Impact of } \\
\text { Sparse and } \\
\text { Dense De- } \\
\text { ployment } \\
\text { of Nodes } \\
\text { Under } \\
\text { Different } \\
\text { Propagation } \\
\text { Models in } \\
\text { Manets }\end{array}$ & $\begin{array}{l}\text { By using NS-2 simulator three radio } \\
\text { propagation models have been used for } \\
\text { evaluation that are Two Ray Ground, } \\
\text { Shadowing and Free Space in sparse } \\
\text { and dense settings of nodes. The per- } \\
\text { formance have been evaluated based on } \\
\text { Average throughput, Average Latency } \\
\text { and Average Packet Drop. Along with } \\
\text { these OLSR (proactive) protocol have } \\
\text { also been used that works on the prin- } \\
\text { ciple of MPR to selection of open and } \\
\text { shortes paths with using its relay strat- } \\
\text { egy. }\end{array}$ & $\begin{array}{l}\text { The proposed work } \\
\text { have given outstand- } \\
\text { ing results in sparse } \\
\text { and dense network } \\
\text { scenarios which has } \\
\text { considered efficient } \\
\text { to the best of our } \\
\text { knowledge }\end{array}$ & $\begin{array}{l}\text { Though, there must } \\
\text { be some lack with } \\
\text { the proposed work } \\
\text { too and the main } \\
\text { reason is that due } \\
\text { the mobility na- } \\
\text { ture fo the nodes in } \\
\text { MANETs the per- } \\
\text { formance may vary } \\
\text { and can't be at best } \\
\text { level continuously. } \\
\text { But, as compared } \\
\text { with the existing } \\
\text { work the proposed } \\
\text { work has shown } \\
\text { remarkable perfor- } \\
\text { mance }\end{array}$ \\
\hline
\end{tabular}

\section{Methodology}

The methodology adopted for conducting research work in wireless and networks domain consists of three approaches i.e. theoretical analysis of data, experiments, and simulations. A descriptive theoretical analysis approach will be followed if the focus of the research study is to present the research problems in a relevant framework. For the manipulation of actual processes, the method of experiments

Altaf Hussain, Tariq Hussain, Iqtidar Ali and Muhammad Rafiq Khan Impact of Sparse and Dense Deployment of Nodes Under Different Propagation Models in Manets
ADCAIJ: Advances in Distributed Computing and Artificial Intelligence Journal Regular Issue, Vol. 9 N. 1 (2020), 61-84 eISSN: 2255-2863 - https://adcaij.usal.es Ediciones Universidad de Salamanca - CC BY-NC-ND 
will be followed by using specific guidelines. When you must check the actual system performance in a series of ways using different parameters and are cost-effective and hardworking the process of simulation will be followed. Simulations are the replications of realism for exploring the model, it offers to arrange and format the algorithm properties (Shutimarrungson \& Wuttidittachotti, 2019).

These research works belong to the latter category which is simulations. Network models and protocols are normally evaluated using different parameters using simulation to check the efficiency and stability of the protocols from different angles and directions. The impacts of different variables are studied using simulation using multiple scenarios for each protocol.

The proposed simulation model and its parameters are depicted in Figure 4. The flow of simulation starts from writing a TCL script composed of simulation parameters of the proposed scenarios. The parameters will be varied in each TCL scripts according to the parameters in Table 2. Each script will be executed multiple times and the average value will be calculated against each evaluation parameter. The result of all simulation scenarios will be recorded for further analysis against the chosen performance metrics. The results will be also incorporated into Microsoft excel for visual comparison based on the varied simulation parameters.

\subsection{Simulation Scenario}

The tool used for simulation in this research study is the popular tool used for carrying out this type of research studies, NS-2 is the widely used tool which has been incorporated into many wireless testbeds and industry standards for carrying out discrete event simulations. The techniques used for analyzing the results will be PERL and AWK scripts using the .tr files generated by running the TCL scripts. Further, the results will be depicted in the form of graphs in Microsoft Excel for visual appearances. The simulation work of this research work can be broadly categorized into three major phases, i.e. Pre simulation phase, Execution Phase, and Post Simulation phase. General and diagrammatic views of these phases are shown in Figure 5.

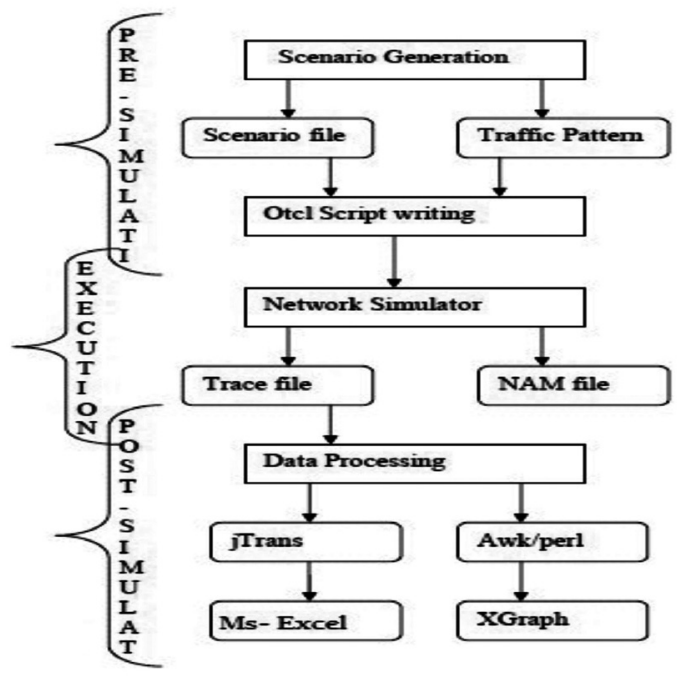

Figure 5: Phases of Simulations

Altaf Hussain, Tariq Hussain, Iqtidar Ali and Muhammad Rafiq Khan Impact of Sparse and Dense Deployment of Nodes Under Different Propagation Models in Manets
ADCAIJ: Advances in Distributed Computing and Artificial Intelligence Journal Regular Issue, Vol. 9 N. 1 (2020), 61-84 eISSN: 2255-2863 - https://adcaij.usal.es Ediciones Universidad de Salamanca - CC BY-NC-ND 


\subsubsection{Pre-Simulation Phase}

The pre simulation phase is the initial phase in which all the parameters are set before the actual work starts. This phase defines that how many simulation scenarios will be created and will be differentiated based on simulation parameters from each other like several hosts in the scenario, topology of the network, mobility models, selection of protocols on different layers, simulation time, terrain size of the network, selection of performance evaluation parameters and much more beyond this. A TCL script will be written composed of the aforementioned parameters and protocols.

\subsubsection{Execution Phase}

The execution phase will accomplish the task of running the simulation script which will be prepared in the previous phase written in OTcl language. After executing the scripts of each simulation scenario two files will be obtained in the form of output i.e. trace and animation file. The trace file is composed of all the events that occurred during the simulation for a specified amount of time such as several packets sent, dropped and received, etc. While the animation file contains the physical and visual layout of the network topology.

\subsubsection{Post Simulation Phase}

The last phase of the simulation process is the post-simulation phase whose purpose is to critically analyze the obtained results and get the required information from the generated files (trace files). Several techniques can be applied to getting the desired information. Perl and awk scripts are the two common techniques used for the analysis of the results obtained from simulation while some people export the trace files to excel for analysis.

\subsection{Simulation Parameters}

Extensive simulations will be carried out to investigate the efficiency and performance of the OLSR scheme under diverse models of propagation. Several simulation scenarios will be tested by varying simulation parameters like various terrain size i.e. Sparse and Dense network size. Secondly, the sparse and dense network will be simulated for each propagation model listed in Table 2 . The simulation will be carried out for taking transport agent as TCP and application layer traffic as FTP. The nodes will be deployed randomly in a simulation area of $500 \mathrm{~m} \times 500 \mathrm{~m}$ area using Random Waypoint as the mobility models with a pause time of 2 seconds. the simulation will last for 100 seconds against each considered scenarios. The simulation will demonstrate how the performance of the OLSR scheme will be affected by the size of the network in diverse scenarios. Further, the outcomes of this study will reveal which propagation model provides better results for sparse and dense network scenarios under OLSR as a routing agent.

Altaf Hussain, Tariq Hussain, Iqtidar Ali and Muhammad Rafiq Khan Impact of Sparse and Dense Deployment of Nodes Under Different Propagation Models in Manets
ADCAIJ: Advances in Distributed Computing and Artificial Intelligence Journal Regular Issue, Vol. 9 N. 1 (2020), 61-84 eISSN: 2255-2863 - https://adcaij.usal.es Ediciones Universidad de Salamanca - CC BY-NC-ND 
Table 2: General Simulation Parameters

\begin{tabular}{l|l}
\hline Simulation Parameters & Values \\
\hline Channel type & Wireless 802.11 \\
Routing Protocol & OLSR \\
\hline Network Size & Sparse and Dense \\
\hline \multirow{2}{*}{ Propagation Models } & Shadowing \\
\cline { 2 - 2 } & Two Ray Ground Free Space \\
\hline \multirow{2}{*}{ Performance Metrics } & Average Throughput (kbps) \\
& Average Latency (ms) \\
\hline Simulation time & Average Packet Drop (packets) \\
\hline Simulation Area & 100 seconds \\
Agent & $500 \mathrm{~m}$ X 500m \\
Number of nodes & Transmission Control Protocol \\
Mobility of nodes & 25,50 \\
Pause Time & $1-$ to-10 m/s \\
\hline
\end{tabular}

\section{Results and Analysis}

This section gives a thorough discussion and analysis of the concerned simulations w.r.t different parameters and simulation scenarios accordingly. In short, this chapter explains the results and analysis with tabular and graphical illustrations for each scenario taken for the simulations.

The environment of MANET provides a variety of matrices for analysis and evaluation of routing protocols. This study analyzed the performance of OLSR to check the effects of well-known three propagation models is shadowing, free space and the two-ray ground where the nodes are mobile and managed through Random Way Point mobility models. Simulation has been carried out using NS-2 with CMU wireless ad hoc network. nodes are randomly scattered forming an ad hoc network of sparse and dense topologies consisting of 25 and 50 nodes respectively. The node moves randomly according to the Random Way Point mobility model in a space of $500 \mathrm{~m}$ X $500 \mathrm{~m}$.

The performance evaluation has been done based on simulation results and analysis by using the standard metrics i.e. average packet drop, Average throughput, and average Latency. The OLSR protocol has been tested by considering the well-known propagation models. The simulation has been carried out by changing the parameters connection pattern and node movement scenarios files for the

Altaf Hussain, Tariq Hussain, Iqtidar Ali and Muhammad Rafiq Khan Impact of Sparse and Dense Deployment of Nodes Under Different Propagation Models in Manets
ADCAIJ: Advances in Distributed Computing and Artificial Intelligence Journal Regular Issue, Vol. 9 N. 1 (2020), 61-84 eISSN: 2255-2863 - https://adcaij.usal.es Ediciones Universidad de Salamanca - CC BY-NC-ND 
sparse and dense environment. The result analysis has been differentiated and evaluated based on each propagation model for sparse and dense networks.

\subsection{Performance Evaluation}

The performance of protocols and algorithms after the simulation can be tested and evaluated based on some criteria i.e. evaluation metrics or parameters in the domain of networks. The performance metrics chosen for this research study are Average Packet drop, Average Latency, and Average throughput.

\subsubsection{Average Throughput (kbps)}

Throughput refers to the number of items or material passing through a system. In the jargon of networks throughput is the amount of data transferred successfully from source to destination in a network in a specified amount of times. Throughput is measured normally in bits/sec. Higher throughput denotes the effectiveness and efficiency of the network (Jubair et al., 2018). This metric can be calculated using Equation 4.

$$
\text { Average Throughput }=\sum_{i=1}^{n} \frac{\text { Received packets i } \times \text { packet size }}{\text { total simulation time }}
$$

Figure 6 and 7 predicts the throughput of Two Ray Ground, Free Space and Shadowing propagation models for the sparse and dense environment using OLSR as routing protocol. It can be seen from the results depicted that; throughput of propagation models doesn't change so much for sparse scenarios. Two ray model assumes that the signal reaches the receiver through two paths, one a lineof-sight path, and the other the path through which the reflected wave is received. The throughput of the sparse scenario for Two rays is less because the two-ray model does not give a good result for a short distance due to the oscillation caused by the constructive and destructive combination of the two rays. The throughput of free spaces decreases in the dense network and more specifically in a highly dense environment. This due to the nature of the Free Space model that free space propagation model assumes the ideal propagation condition that there is only one clear line-of-sight path between the transmitter and receiver. The values of is portrayed in Figure 2 is a graphical representation. Every propagation model has given different values in average throughput (kbps). Two ray ground has given 554.8 (kbps) values, while Free Space has given 558.5 (kbps) and Shadowing has given 535.7 (kbps) values in Sparse Environment. It was supposing that two ray ground will give better results from the perspective of average throughput (kbps) but since the nodes are mobile and they can come closer to each other. So, the nodes are closer to each other than two ray ground model gives poor result because its signals create oscillations that cause low throughput and free space has given better result because the node comes closer to each other. To be duly noted that free space gives better results in a scenario when there is clear LoS from a source node to the destination node.

Altaf Hussain, Tariq Hussain, Iqtidar Ali and Muhammad Rafiq Khan Impact of Sparse and Dense Deployment of Nodes Under Different Propagation Models in Manets
ADCAIJ: Advances in Distributed Computing and Artificial Intelligence Journal Regular Issue, Vol. 9 N. 1 (2020), 61-84 eISSN: 2255-2863 - https://adcaij.usal.es Ediciones Universidad de Salamanca - CC BY-NC-ND 


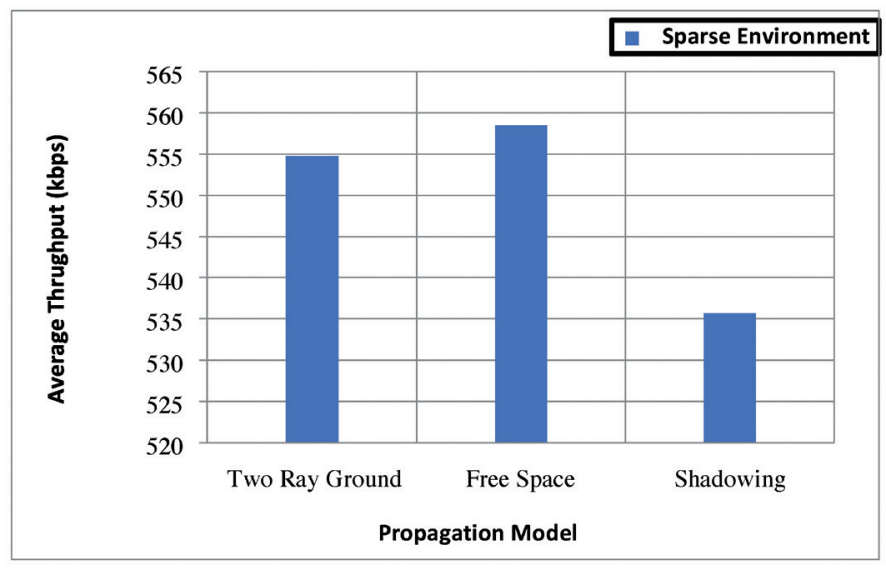

Figure 6: Average Throughput (kbps) of Sparse Environment

It must, however, be mentioned that the increase in throughput for Two rays is interesting from a relative view because this study doesn't work for optimization. This study tried to determine and evaluate the protocol for propagation models under the mobility factor for sparse and dense networks. It was concluded from the simulation results that for FTP type traffic using OLSR as routing agent the deterministic models i.e. Two rays and Free Space have less impact on the throughput as compared to the probabilistic model i.e. Shadowing. The overall results in all scenarios show that the performance of the Free space model performs better among the considered models and it is the model of choice in present circumstances. The values of Table 3 are portrayed in Figure 9 is a graphical representation. Every propagation model has given different values in average throughput (kbps). Two ray ground has given 440.2 (kbps) values, while Free Space has given 517.4 (kbps) and Shadowing has given 496.6 (kbps) values in Dense Environment.

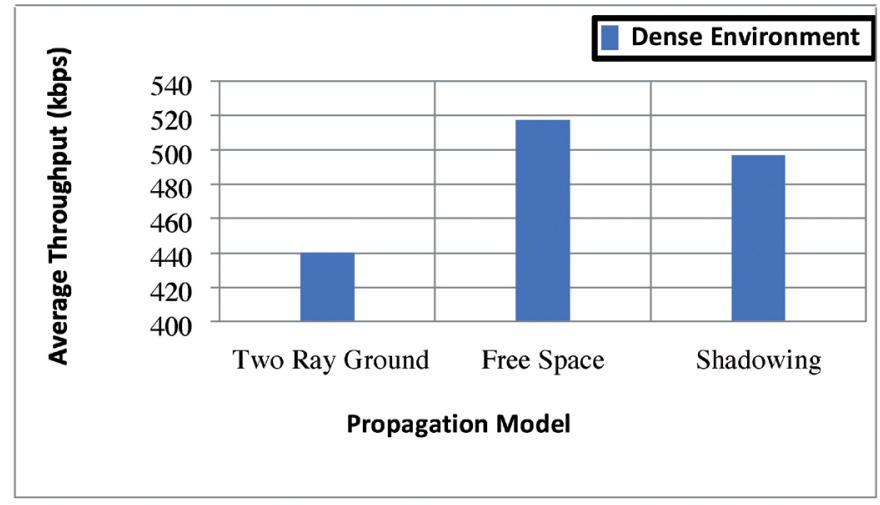

Figure 7: Average Throughput (kbps) of Dense Environment

Altaf Hussain, Tariq Hussain, Iqtidar Ali and Muhammad Rafiq Khan Impact of Sparse and Dense Deployment of Nodes Under Different Propagation Models in Manets
ADCAIJ: Advances in Distributed Computing and Artificial Intelligence Journal Regular Issue, Vol. 9 N. 1 (2020), 61-84 eISSN: 2255-2863 - https://adcaij.usal.es Ediciones Universidad de Salamanca - CC BY-NC-ND 


\subsubsection{Average Latency (ms)}

Network Latency refers to indicate any type of delay that happens during the communication over the network. Specifically, the time is taken by a packet until the departure from a source node in a network until the arrival at the destination (Jubair et al., 2018). This metric can be calculated using Equation 5.

$$
\text { Average Latency }=\sum_{i=1}^{n} \frac{\text { received time } i-\text { sent time } i}{\text { Total data }}
$$

By analyzing the simulation results it is observed that the average latency of two ray ground is relatively high initially in a sparse scenario with low mobility. This increase in delay leads to lower throughput as shown in Figures 8 and 9. The average latency of shadowing and free space go neck to neck initially in sparse networks with both mobility speed and a negligible difference has been observed in dense networks. While the delay for two ray ground changes from scenario to scenario. It can be observed from Figure 5 and 4 that average latency increases, for all the propagation models under consideration as the network goes from sparse to dense.

A slight increase has been noticed in the dense network for low mobility. This happens because of the increased probability of collisions and packet drops due to network congestion when traffic load and network density increases. Generally, as the scenario is dense, the nodes in the network the route changes quickly and more frequently in high mobility which further leads to more link breakages which eventually impact the delay of the network. It can be concluded from the graphs of average latency that the overall performance of two ray ground is acceptable as compared to shadowing and free space, while free space achieved slightly better results than shadowing. In terms of average latency, the impact of two ray ground is acceptable and the results are satisfactory in the concerned considerations. Shadowing model too has the worst delay characteristics because of the loss of packets information with respective nodes. The values of is portrayed in Figure 8 is a graphical representation. Every propagation model has given different values in average latency (millisecond). Two ray ground has given 0.323 (millisecond) values, while Free Space has given 0.527 (millisecond) and Shadowing has given 0.482 (millisecond) values in Sparse Environment.

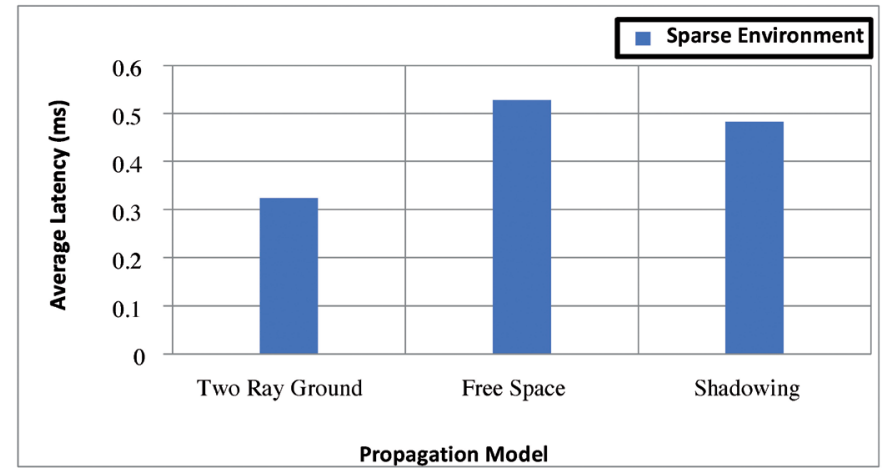

Figure 8: Average Latency (ms) of Sparse Environment

Altaf Hussain, Tariq Hussain, Iqtidar Ali and Muhammad Rafiq Khan Impact of Sparse and Dense Deployment of Nodes Under Different Propagation Models in Manets
ADCAIJ: Advances in Distributed Computing and Artificial Intelligence Journal Regular Issue, Vol. 9 N. 1 (2020), 61-84 eISSN: 2255-2863 - https://adcaij.usal.es Ediciones Universidad de Salamanca - CC BY-NC-ND 


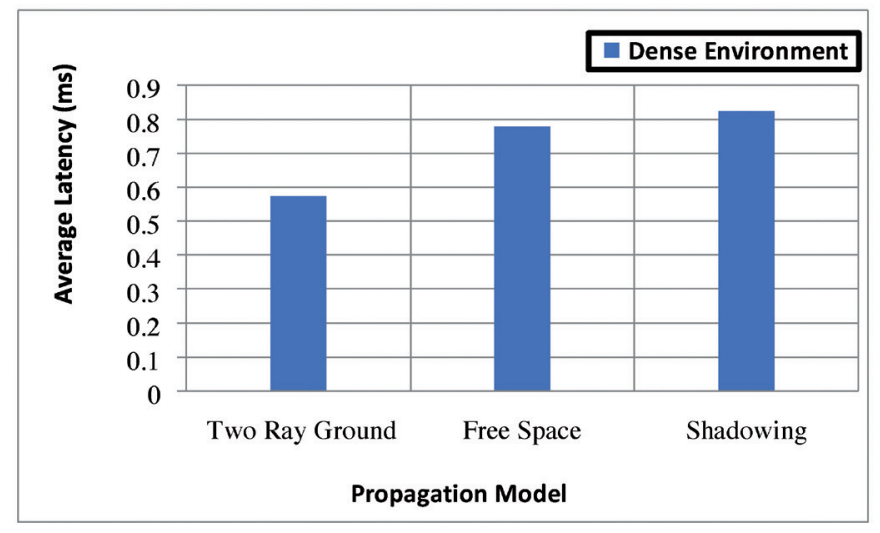

Figure 9: Average Latency (ms) of Dense Environment

Figures 8 and 9 show the average latency of the sparse environment for the proposed scenarios. Since the nodes are movable, so due to the mobility of nodes two ray ground models have given better results in contrast to the other two propagation models. The values portrayed in Figure 5 is a graphical representation. Every propagation model has given different values in average latency (millisecond). Two ray ground has given 0.572 (millisecond) values, while Free Space has given 0.778 (millisecond) and Shadowing has given 0.825 (millisecond) values in Dense Environment.

\subsubsection{Average Packet Drop (packets)}

Average Packet drop refers to the amount of an average number of packets that have been dropped or lost during transmission of data traveling in a network from one place to another. Drops are typically caused by transmission errors, a collision in wireless network and congestion in the network (Jubair et al., 2018). This metric can be calculated using Equation 6.

$$
\text { Packet Drop }=\sum_{i=1}^{n} \frac{\text { Packet_Dropped } \times \text { Packet_Size }}{\text { Total Time }}
$$

The outcomes of the simulation results show that the number of packets discarded or dropped in a dense network is high as compared to sparse. According to Figure 6, in dense scenarios, the probability of collision is high due to channel contention and interference which further results in packet drop. It can be observed from the graph that the performance of two rays is better by dropping fewer packets. While the average number of packets dropped by free space is quite higher from two ray as well as shadowing. The values portrayed in Figure 10 as a graphical representation. Every propagation model has given different values in average packet drop (packets). Two ray ground has dropped 206 (packets) values, while Free Space has dropped 386 (packets) and Shadowing has dropped 333 (packets) in the proposed Sparse Environment.

Altaf Hussain, Tariq Hussain, Iqtidar Ali and Muhammad Rafiq Khan Impact of Sparse and Dense Deployment of Nodes Under Different Propagation Models in Manets
ADCAIJ: Advances in Distributed Computing and Artificial Intelligence Journal Regular Issue, Vol. 9 N. 1 (2020), 61-84 eISSN: 2255-2863 - https://adcaij.usal.es Ediciones Universidad de Salamanca - CC BY-NC-ND 


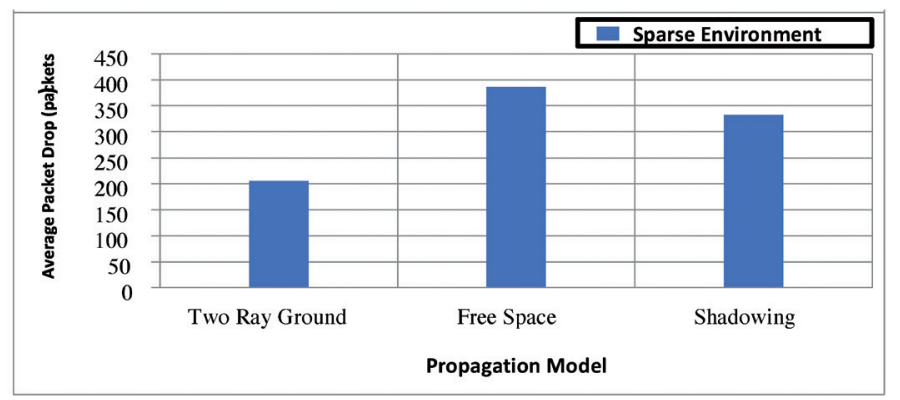

Figure 10: Average Packet Drop (packets) of Sparse Environment

It is revealed clearly from Figure 10 that the Two Ray Ground model has given much better results in less packet drop scenario in contrast to the other two propagation models. This study tried to determine and evaluate the protocol for propagation models under the mobility factor for sparse and dense networks. It was concluded from the simulation results that for FTP type traffic using OLSR as routing agent the deterministic models i.e. Two rays and Shadowing have less impact on the average packet drop as compared to probabilistic model i.e. Free Space model. The overall results in all scenarios show that the performance of the Two Ray Ground model performs better among the considered models and it is the model of choice in present circumstances. The values portrayed in Figure 11 is a graphical representation. Every propagation model has given different values in average packet drop (packets). Two ray ground has dropped 581 (packets) values, while Free Space has dropped 608 (packets) and Shadowing has dropped 447 (packets) in Dense Environment.

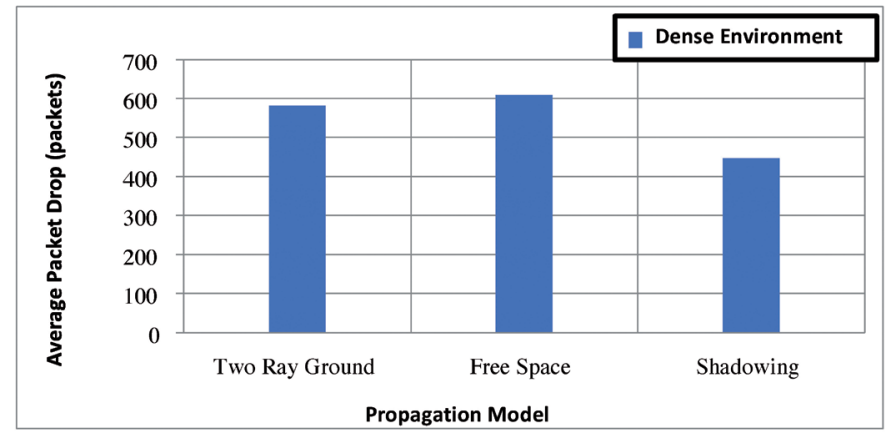

Figure 11: Average Packet Drop (packets) of Dense Environment

Shadowing effect assumes that the signal level can vary widely for a given distance between two nodes. This increases the probability that the signal level may go below a certain required level called a threshold level. In this case, a receiving mobile node may not successfully receive a packet. After that, the received signal level goes below a threshold level. Hence there will be packet losses in the network if a network is large enough to have average link distance greater than about 200. The Free Space poor performance is due to the low intensity of the signal caused by the obstacles. This results in the packet loss on weak links display wrongly the links disconnection and lead to the interruption. In contrast, the performance of free space is comparatively high when latency and throughput are considered a metric.

Altaf Hussain, Tariq Hussain, Iqtidar Ali and Muhammad Rafiq Khan Impact of Sparse and Dense Deployment of Nodes Under Different Propagation Models in Manets
ADCAIJ: Advances in Distributed Computing and Artificial Intelligence Journal Regular Issue, Vol. 9 N. 1 (2020), 61-84 eISSN: 2255-2863 - https://adcaij.usal.es Ediciones Universidad de Salamanca - CC BY-NC-ND 


\subsection{Summarized Results}

By combining all propagation models' results and evaluating the average values of average throughput (kbps), average latency (ms) and average packet drop (packets) for sparse and dense scenarios. It has been concluded that every propagation model has performed well according to the best adaptable environment as shown in Table 3. This table depicts the average values of both sparse and dense environments. The summarized results show the merge values on average of both sparse and dense environments.

Table 3: Summarized Average Results in Tabular Form

\begin{tabular}{|c|c|c|c|}
\hline $\begin{array}{c}\text { Propagation } \\
\text { Model }\end{array}$ & $\begin{array}{c}\text { Average Throughput } \\
\text { (kbps) }\end{array}$ & $\begin{array}{c}\text { Average Latency } \\
\text { (ms) }\end{array}$ & $\begin{array}{c}\text { Average Packet Drop } \\
\text { (packets) }\end{array}$ \\
\hline Two Ray Ground & 497.5 & 0.4475 & 393.5 \\
\hline Free Space & 537.95 & 0.6525 & 497 \\
\hline Shadowing & 516.15 & 0.6535 & 390 \\
\hline
\end{tabular}

The values of Table 3 are illustrated in the following Figures. For sparse and dense environments, the overall average values have been calculated and portrayed in the given Figures 14, 15 and 16. Figure 16 denotes the average throughput in kbps of sparse and dense environments under the proposed three propagation model is shadowing, free space and two-ray ground.

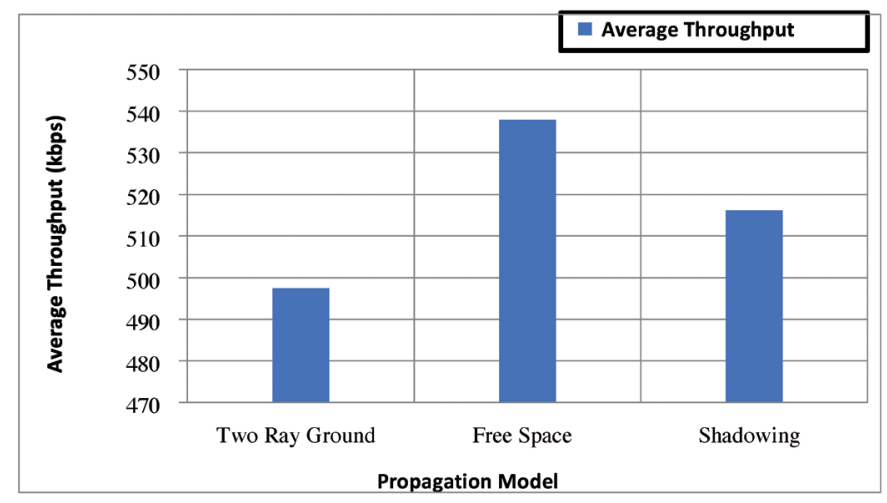

Figure 12: Average Throughput (kbps) of Sparse and Dense

From Figure 12 it can be witnessed that the average throughputs in kbps of two-ray ground models have given poor results. Because the nodes can traverse from one place to another due to nodes mobility that's why they often come to close range and Two Ray propagation model does not give a better result when the nodes are close to each other. But the main motive was to assess and analyze the impact of these propagation models under sparse and dense settings of nodes. From Figure 8 it has also verified that Two Ray model can be used in settings where nodes have long ranges from each other's

Altaf Hussain, Tariq Hussain, Iqtidar Ali and Muhammad Rafiq Khan Impact of Sparse and Dense Deployment of Nodes Under Different Propagation Models in Manets
ADCAIJ: Advances in Distributed Computing and Artificial Intelligence Journal Regular Issue, Vol. 9 N. 1 (2020), 61-84 eISSN: 2255-2863 - https://adcaij.usal.es Ediciones Universidad de Salamanca - CC BY-NC-ND 
from meters up to kilometers range but still it has given $67 \%$ results out of $100 \%$. Figure 13 illustrates the average latency in milliseconds of sparse and dense environments under the proposed three propagation model is shadowing, free space and two-ray ground.

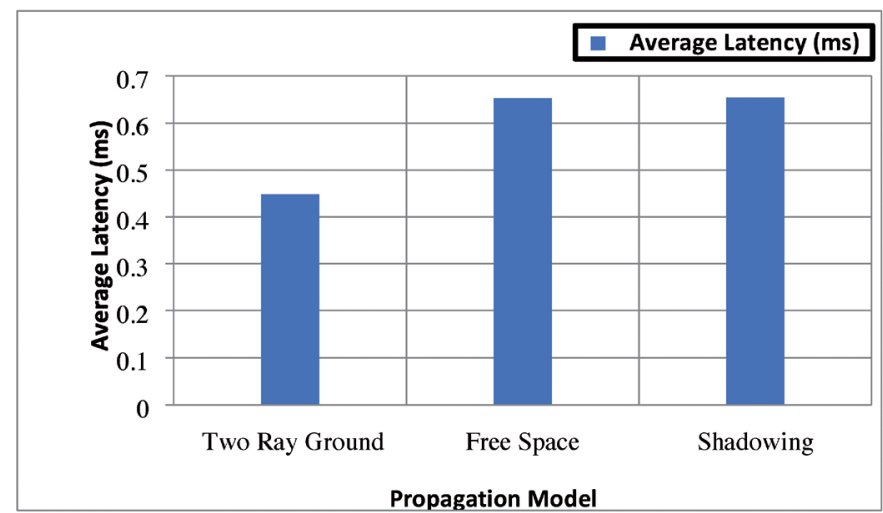

Figure 13: Average Latency (ms) of Sparse and Dense

Figure 14 denotes the average packet drop in packets of sparse and dense environments under the proposed three propagation model is shadowing free space and two ray ground.

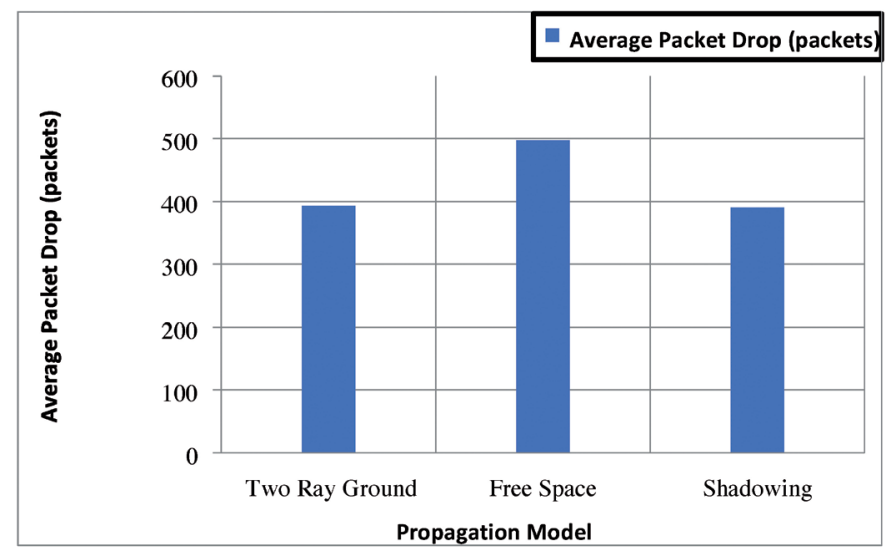

Figure 14: Average Packet Drop (packets) of Sparse and Dense

\section{Conclusion}

This section gives summary, conclusion, contribution, and recommendation along with future work of the proposed mechanism and it also concludes the research. The impact of different radio propagation models on the performance of ad hoc networks. According to the simulation findings, we may state that the choice of the propagation models has a great impact on the routing protocol's

Altaf Hussain, Tariq Hussain, Iqtidar Ali and Muhammad Rafiq Khan Impact of Sparse and Dense Deployment of Nodes Under Different Propagation Models in Manets
ADCAIJ: Advances in Distributed Computing and Artificial Intelligence Journal Regular Issue, Vol. 9 N. 1 (2020), 61-84 eISSN: 2255-2863 - https://adcaij.usal.es Ediciones Universidad de Salamanca - CC BY-NC-ND 
performance. The simulation findings have revealed that the different propagation models have a considerable impact on the performance of the ad hoc mobile network. This research study presented the performance evaluation of OLSR protocol under varied propagation models with sparse and dense network topologies. The analysis has been made to identify and find out how much impact each propagation model has on the performance of the protocol in chosen dense and sparse networks. Different performance results have been obtained against the selected propagation models. The protocol has been evaluated using performance metrics i.e. Average throughput, average end-to-end delay, and average packet drop. The results indicate that the effect of fading increases with the speed of mobile nodes. The analysis of simulation results is performed based on the three previously defined metrics. Simulation is performed by changing the node's mobility concerning two different scenarios: sparse and dense networks with keeping varying mobility speed for both. From the simulation results, the choice of propagation models has a great impact on the performance of the routing protocol, so realistic and representative propagation models are necessary as far as the accurate analysis of the performance routing protocols is concerned. The simulation results revealed that the different propagation models affected the performance of the mobile ad hoc network considerably. Consequently, different performance evaluation results were obtained.

In the future, these topologies can be tested under different propagation models with different mobility models in MANETs. network stability period, path loss, jitter, energy consumption are used for performance evaluation parameters.

Authors' contributions: All the authors contributed to this research. The order of authors in this manuscript is maintained depending on the level of contributions they made in this research.

Conflicts of Interest: The authors declared that they have no conflicts of interest.

\section{References}

Alnumay, W., Ghosh, U., \& Chatterjee, P. (2019). A Trust-Based predictive model for mobile ad hoc network in internet of things. Sensors, 19(6), 1467.

Amjad, K., Ali, M., Jabbar, S., Hussain, M., Rho, S., \& Kim, M. (2015). Impact of dynamic path loss models in an urban obstacle aware ad hoc network environment. Journal of Sensors, 2015.

Bhoyroo, M., \& Bassoo, V. (2016). Performance evaluation of Nakagami model for Vehicular communication networks in developing countries. Paper presented at the 2016 IEEE International Conference on Emerging Technologies and Innovative Business Practices for the Transformation of Societies (EmergiTech).

Chattopadhyay, A. S., \& Agarwal, N. (2018). Performance Analysis of Different Routing Protocols for Mobile Ad-Hoc Network. IOSR Journal of Engineering (IOSRJEN), 8(7), 20-27.

Clausen, T., \& Jacquet, P. (2003). RFC3626: Optimized link state routing protocol (OLSR): RFC Editor.

Corson, S. (1999). Mobile ad hoc networking (MANET): Routing protocol performance issues and evaluation considerations. IETF RFC2501.

DE, C. (2003). High throughput Path Metric for multi-hop wireless networks. Paper presented at the ACM MobiCom, 2003.

Altaf Hussain, Tariq Hussain, Iqtidar Ali and Muhammad Rafiq Khan Impact of Sparse and Dense Deployment of Nodes Under Different Propagation Models in Manets
ADCAIJ: Advances in Distributed Computing and Artificial Intelligence Journal Regular Issue, Vol. 9 N. 1 (2020), 61-84 eISSN: 2255-2863 - https://adcaij.usal.es Ediciones Universidad de Salamanca - CC BY-NC-ND 
Dhoutaut, D., Régis, A., \& Spies, F. (2006). Impact of radio propagation models in vehicular ad hoc networks simulations. Paper presented at the Proceedings of the 3rd international workshop on Vehicular ad hoc networks.

Draves, R., Padhye, J., \& Zill, B. (2004). Routing in multi-radio, multi-hop wireless mesh networks. Paper presented at the Proceedings of the 10th annual international conference on Mobile computing and networking.

Gruber, I., Knauf, O., \& Li, H. (2004). Performance of ad hoc routing protocols in urban environments. Paper presented at the Proceedings of European Wireless.

Jacquet, P., Muhlethaler, P., Clausen, T., Laouiti, A., Qayyum, A., \& Viennot, L. (2001). Optimized link state routing protocol for ad hoc networks. Paper presented at the Proceedings. IEEE International Multi Topic Conference, 2001. IEEE INMIC 2001. Technology for the 21st Century.

Jubair, M., Khaleefah, S., Mostafa, S., \& Mustapha, A. (2018). Performance Evaluation of AODV and OLSR Routing Protocols in MANET Environment. International Journal on Advanced Science, Engineering and Information Technology.

Katagiri, K., Onose, K., Sato, K., Inage, K., \& Fujii, T. (2019). Highly accurate prediction of radio propagation using model classifier. Paper presented at the 2019 IEEE 89th Vehicular Technology Conference (VTC2019-Spring).

Khan, L. U., Khan, F., Khan, N., Khan, M. N., \& Pirzada, B. (2013). Effect of network density on the performance of MANET routing protocols. Paper presented at the 2013 International Conference on Circuits, Power and Computing Technologies (ICCPCT).

Khan, M., Majeed, M. F., \& Muhammad, S. (2017). Evaluating radio propagation models using destination-sequenced distance-vector protocol for MANETs. Bahria University Journal of Information \& Communication Technologies (BUJICT), 10(1).

Khandakar, A. (2012). Step by step procedural comparison of DSR, AODV and DSDV routing protocol. Paper presented at the International Proceedings of Computer Science \& Information Tech.

Malik, A., Verma, H. K., \& Pal, R. (2012). Impact of Firewall and VPN for securing WLAN. International Journal, 2(5).

Mishra, M., Dash, P. K., Hota, L., \& Panda, M. (2017). Analyze the network layer protocols on the basis of mobility, pause time and simulation time in MANET. Paper presented at the 2017 IEEE International Conference on Power, Control, Signals and Instrumentation Engineering (ICPCSI).

Nabou, A., Laanaoui, M. D., \& Ouzzif, M. (2018). The effect of transmit power on MANET routing protocols using AODV, DSDV, DSR and OLSR in NS3. Paper presented at the International Conference on Advanced Intelligent Systems for Sustainable Development.

Pal, A., Dutta, P., Chakrabarti, A., Singh, J. P., \& Sadhu, S. (2019). Biogeographic-based temporal prediction of link stability in mobile ad hoc networks. Wireless personal communications, 104(1), 217-233.

Patil, V. C. (2016). Performance evaluation of MANET protocols: A propagation model perspective. Paper presented at the 2016 2nd International Conference on Applied and Theoretical Computing and Communication Technology (iCATccT).

Poonia, R. C. (2017). Viability Analysis of TwoRayGround and Nakagami Model for Vehicular Ad-Hoc Networks. International Journal of Applied Evolutionary Computation (IJAEC), 8(2), 44-57.

Prakash, J., Gupta, D. K., \& Kumar, R. (2017). Soft computing based cluster-head selection in mobile ad-hoc network. Journal of Artificial Intelligence, 10(3), 98-111.

Altaf Hussain, Tariq Hussain, Iqtidar Ali and Muhammad Rafiq Khan Impact of Sparse and Dense Deployment of Nodes Under Different Propagation Models in Manets
ADCAIJ: Advances in Distributed Computing and Artificial Intelligence Journal Regular Issue, Vol. 9 N. 1 (2020), 61-84 eISSN: 2255-2863 - https://adcaij.usal.es Ediciones Universidad de Salamanca - CC BY-NC-ND 
Rahul, R., Bansal, B., \& Kapoor, R. (2019). Performance Analysis of Empirical Radio Propagation Models in Wireless Cellular Networks. World Scientific News, 121, 40-46.

Sarkar, T. K., Ji, Z., Kim, K., Medouri, A., \& Salazar-Palma, M. (2003). A survey of various propagation models for mobile communication. IEEE Antennas and propagation Magazine, 45(3), 51-82.

Schmitz, A., \& Wenig, M. (2006). The effect of the radio wave propagation model in mobile ad hoc networks. Paper presented at the Proceedings of the 9th ACM international symposium on Modeling analysis and simulation of wireless and mobile systems.

Shutimarrungson, N., \& Wuttidittachotti, P. (2019). Realistic propagation effects on wireless sensor networks for landslide management. EURASIP Journal on Wireless Communications and Networking, 2019(1), 1-14.

Sood, N., Baroudi, S., Zhang, X., Liebeherr, J., \& Sarris, C. D. (2018). Integrating physics-based wireless propagation models and network protocol design for train communication systems. IEEE Transactions on Antennas and Propagation, 66(12), 6635-6645.

Venkataramana, A., Rao, J. V., \& Setty, S. P. (2015). Impact of propagation models on QoS issues of routing protocols in mobile ad hoc networks. Paper presented at the Emerging ICT for Bridging the Future-Proceedings of the 49th Annual Convention of the Computer Society of India CSI Volume 2.

Xiang, S., \& Yang, J. (2018). Performance reliability evaluation for mobile ad hoc networks. Reliability Engineering \& System Safety, 169, 32-39.

Zhihua, L., \& Bing, X. (2019). Method for predicting indoor three-dimensional space signal field strength using an outdoor-to-indoor propagation model: Google Patents.

Altaf Hussain, Tariq Hussain, lqtidar Ali and Muhammad Rafiq Khan

Impact of Sparse and Dense Deployment of Nodes

Under Different Propagation Models in Manets
ADCAIJ: Advances in Distributed Computing and Artificial Intelligence Journal Regular Issue, Vol. 9 N. 1 (2020), 61-84 eISSN: 2255-2863 - https://adcaij.usal.es Ediciones Universidad de Salamanca - CC BY-NC-ND 